\title{
New Online Shunt Acidification for Water Injection Increasing Technology and Its Application in Huanjiang Oilfield
}

\author{
Zhiying Deng $\mathbb{D}^{1},{ }^{1,2,3}$ Zhenning Ji, ${ }^{2,3}$ Suiwang Zhang, ${ }^{2,3}$ Lingpu He, ${ }^{4}$ Xiaobing Lu, $^{2,3}$ \\ Wenchao Wu, ${ }^{5}$ Liwei Xiong, ${ }^{1}$ and Haiming Fan ${ }^{6}{ }^{6}$ \\ ${ }^{1}$ Hubei Key Laboratory of Plasma Chemistry and Advanced Materials, Wuhan Institute of Technology, Wuhan 430205, China \\ ${ }^{2}$ National Engineering Laboratory for Exploration and Development of Low-permeability Oil and Gas Field, Xi'an 710018, China \\ ${ }^{3}$ Oil \& Gas Technology Research Institute of Changqing Oil Field Company, Xi'an 710018, China \\ ${ }^{4}$ The 4th Oil Production Plant of Changqing Oil Field Company, Yinchuan 750000, China \\ ${ }^{5}$ Shanxi Ming De Petroleum Technology Limited Company, Xi'an 710018, China \\ ${ }^{6}$ Shandong Key Laboratory of Oilfield Chemistry, School of Petroleum Engineering, China University of Petroleum (East China), \\ Qingdao 266580, Shandong, China
}

Correspondence should be addressed to Zhiying Deng; fhmwd@163.com

Received 20 June 2020; Accepted 2 September 2021; Published 10 December 2021

Academic Editor: Kaustubha Mohanty

Copyright (C) 2021 Zhiying Deng et al. This is an open access article distributed under the Creative Commons Attribution License, which permits unrestricted use, distribution, and reproduction in any medium, provided the original work is properly cited.

The poor physical property and strong heterogeneity of Triassic Yanchang formation in Huanjiang oilfield of Ordos Basin are the main reasons for uneven water absorption, partial injection wells underinjection at high pressure, and decline of production. Previously, large numbers of conventional acidifications were used for plugging removal in the reservoir, but the effect was not so good and effective period was short. Aiming at the geological characteristics of Huanjiang oilfield, an online shunt acidification and augmented injection technology which does not stop water injection, pull original production strings out, and continuously inject acid and diverting agent has been proposed. A chelating acid COA-1S with low corrosion rate $\left(0.3675 \mathrm{~g} /\left(\mathrm{m}^{2} \cdot \mathrm{h}\right)\right)$, good retardation capacity (hydrolysis constant $=1.2 \times 10^{-6}$ ), and effective chelating ability (precipitation inhibition rate $>95 \%$ ) has been developed, as well as a diverting agent COA-1P with good dispersion in acid solution, diversion effect, and particle size $(10-100 \mu \mathrm{m})$, which behaves well in COA-1S acid. It has been proved that the online acid system has a good diversion acidizing ability and plugging removal performance in a deep area in the laboratory core physical simulation test. The field test results show that the online shunt acidizing and augmented injection technology could reduce the injection pressure significantly (4.2 MPa) and increase water injection by $10 \mathrm{~m}^{3} / \mathrm{d}$ for the measured well (H5) and improve the water injection profile prominently. The online shunting acidification and augmented injection technology have the following advantages: simple procedures, fewer equipment needed, high efficiency of depressurization, and increasing water injection, which could effectively improve the profile of water wells, and there is a bright future of the technology.

\section{Introduction}

The main development layer of Huanjiang oilfield is the Triassic Yanchang formation, the average porosity of the reservoir is $10.9 \%$, and the average permeability is $0.43 \times 10^{-3} \mu \mathrm{m}^{2}$, so Huanjiang oilfield belongs to the ultra-low-permeability sandstone reservoir. Due to poor physical properties of the reservoir and injected water not up to standard, as well as other reasons, many problems such as uneven water absorption, increasing water injection pressure, and more and more injecting wells underinjection have arised. In recent years, aiming at the problem of underinjection of Huanjiang oilfield, a series of measures have been carried out to reduce water injection pressure and increase water injection and have achieved great efforts; however, the effective period of these measures is short (average 79 days) and effective rate is low (average 73\%). 
The main reasons are as follows: (1) because of the repeated acidification of wells, the damaging radius is getting bigger; (2) after acidification, the acid solution produced secondary damage and caused secondary blockage to the reservoir, and (3) due to strong heterogeneity of the reservoir, acid absorption of different layers varies and low-permeability layers absorb fewer acid, resulting in poor acidification effect [1].

Based on the geological characteristics of Huanjiang oilfield, an online shunt acidification and augmented injection technology with not stopping water injection, not pulling out the original production strings, and continuous injection of acid have been proposed. The field test results showed that the technology behaves well, which could greatly reduce the water injection, improve the water injection volume, and effectively improve the profile of the wells. It has a good application prospect, and there is a bright future of the technology $[2,3]$.

\section{Analysis of the Theory and Adaptability of Online Diversion Acidification}

2.1. Shunt Acidizing Theory. Generally, acid flows through the small layers linearly should obey Darcy law. In order to make the acid move into the per small layer (or small section) and reach the goal of plugging removal in each layer (section) proportionately, it must obey the rule that the acid injection rate on per unit area of small layers (or small section) is the same [4], which means it should meet the following relation:

$$
\frac{K_{1} \Delta P_{1}}{\mu_{1} L_{1}}=\frac{K_{2} \Delta P_{2}}{\mu_{2} L_{2}}=\cdots=\frac{K_{i} \Delta P_{i}}{\mu_{i} L_{i}}=\cdots=\frac{K_{N} \Delta P_{N}}{\mu_{N} L_{N}} .
$$

In the relation, $K$ - permeability, $10^{-3} \mu \mathrm{m}^{2} ; \Delta P$ - pressure difference, $\mathrm{MPa} ; \mu$-injection viscosity, $\mathrm{mPa} \cdot \mathrm{s} ; L$ - distance of pressure differential, $\mathrm{m}^{3}$; and $\mathrm{N}$ - total amount of layers.

Due to the affect of damage degree, reservoir pressure, fluid compressibility, fluid viscosity, and natural seam hole development of small layers (or small section) [5], when measures are not taken, the relation is not met; therefore, temporary plugging or shunt technology should be considered.

The online shunt acidification is an injection process which does not need to pull the original pipes out during acidification; meanwhile, acid and diverting agent are injected together with water. In the early stage, the acid prefers to enter the high-permeability layer, as the effect of the diverting agent, permeability of high permeability layer would decrease with increase entering of diverting agent, therefore, the subsequent acid would rather enter other layers with low permeability, and finally, the goal of acid entering into all layers proportionally is achieved [6].

2.2. Performance Evaluation of Chelating Acid. Chelate acid (COA-1S) is a kind of multivariant organic acid, with 24 $\mathrm{O}^{2-}, 12 \mathrm{OH}^{-}$and $6 \mathrm{PO}_{3}{ }^{-}$, and $\mathrm{N}$ and $\mathrm{O}$ heteroatoms which contain unshared electron pairs with the greater electronegativity, and when the groups encounter $\mathrm{Ca}^{2+}, \mathrm{Ba}^{2+}, \mathrm{Sr}^{2+}$, $\mathrm{Fe}^{3+}$, and other high-valence metal cations, stable complexes are easily generated, which are very stable in the wide range of $\mathrm{pH}$ value [7]. Table 1 shows the chelating performance of the acid solution. It can be seen that compared with mud acid and multihydrogen acid, chelate acid (COA-1S) is superior in inhibiting precipitation, with the $\mathrm{pH}$ value of the solution increased from 3 to 7 , the precipitation inhibition rate of $\mathrm{COA}-1 \mathrm{~S}$ to $\mathrm{Ba}^{2+}$ increases rapidly, indicating the increase of $\mathrm{pH}$ value caused by acid consumption does not reduce chelating ability, and the resulting complex are stable enough to prevent the secondary precipitate.

The hydrolysis equilibrium constant of chelate acid (COA-1S) is only about $1.2 \times 10^{-6}$; therefore, the concentration of chelating acid is very low when hydrolysis equilibrium is reached, and the hydrolysis reaction process is slow. In the process of acidizing and plugging removal, in order to maintain the equilibrium of hydrolysis, the ionized $\mathrm{H}^{+}$generally reacts with sandstone minerals, thus slowing down the reaction rate of acid and rock and achieving the goal of plugging removal in the deep area. Comparing with conventional mud acid, the superior performance in retardation of COA-1S provides a guarantee for improving the acidification effect in the deep area.

Referring to the SY/T 5405-1996 "Performance test method and evaluation index of corrosion inhibitor for acidification," the corrosion rate of COA-1S (50\%) for N80 steel sheet and tube column coated is determined under $60^{\circ} \mathrm{C}$, and the corrosion rates are $0.2895 \mathrm{~g} /\left(\mathrm{m}^{2} \cdot \mathrm{h}\right)$ and $0.3675 \mathrm{~g} /\left(\mathrm{m}^{2} \cdot \mathrm{h}\right)$, respectively, and the results are only $10 \%$ of the industry standard level $\left(3.0 \mathrm{~g} /\left(\mathrm{m}^{2} \cdot \mathrm{h}\right)\right.$, which indicates that COA-1S has less corrosion to inner tubes, and the pictures of steel sheets before and after corrosion tests (shown in Figure 1) also support the standpoint.

2.3. Performance Evaluation of the Diverting Agent. The diverting agent COA-1P is a kind of salt substance, which is a colorless transparent liquid with a density of $1.07 \mathrm{~g} / \mathrm{cm}^{3}$. Figure 2 shows solubility evaluation results of the diverting agent. It can be seen that the solution is clear and transparent when diverting agent COA-1P mixes with tap water, and when mixing diverting agent COA-1P with the chelate acid COA-1S, uniform and dispersed white small particles are produced. With the increase in the amount of tap water, the $\mathrm{pH}$ value of the solution increases gradually, and the white particles gradually dissolve and are completely dissolved when the $\mathrm{pH}$ value is 7 . During onsite operation, firstly, the chelate acid COA-1S should be injected into the formation to remove pollution in the zone; secondly, the diverting agent is added to produce chemical particles to form temporary plugging; thirdly, chelate acid COA-1S is injected again to be forced to flow to the low-permeability zone, aiming at improving the longitudinal water absorption section of water injection wells; finally, the normal water injection is recovered to relieve the blockage of the diverting agent to the high-permeability zone.

In order to fully understand the distribution of the particle size of the diverting agent COA-1P in the acid solution, the particle size distribution of COA-1S and COA$1 \mathrm{P}$ mixed solution with different concentration is detected 
TABLE 1: The chelating performance of chelate acid COA-1S and other acids.

\begin{tabular}{|c|c|c|c|c|c|c|c|}
\hline \multirow{2}{*}{ Sample } & \multicolumn{4}{|c|}{ Scale inhibition rate to $\mathrm{BaSO}_{4}(\%)$} & \multicolumn{3}{|c|}{ Inhibition rate $(\%)$} \\
\hline & $\mathrm{pH}=3$ & $\mathrm{pH}=5$ & $\mathrm{pH}=6$ & $\mathrm{pH}=7$ & $\mathrm{CaF}_{2}$ & $\mathrm{Fe}(\mathrm{OH})_{3}$ & Fluoroaluminate \\
\hline Mud acid & 0.73 & 0.76 & 0.79 & 0.68 & - & - & - \\
\hline Multihydrogen acid & 3.41 & 5.58 & 7.39 & 9.38 & 60.72 & 36.26 & 31.45 \\
\hline COA-1S & 15.62 & 64.37 & 78.69 & 89.37 & 98.81 & 96.62 & 96.72 \\
\hline
\end{tabular}

\begin{tabular}{cccc}
\hline \multicolumn{4}{c}{ Acid type COA : water=1:1 } \\
\hline $\begin{array}{c}\text { N80 steel } \\
\text { sheet }\end{array}$ & Tube column & $\begin{array}{c}\text { N80 steel } \\
\text { sheet }\end{array}$ & Tube column \\
\hline & & & \\
\hline
\end{tabular}

FIgURE 1: Pictures before and after corrosion tests of steel sheets.

by using a laser particle size analyzer. The results are shown in Table 2. It can be seen from Table 2 that the resulting white particle size is mainly from 10 to $100 \mu \mathrm{m}$, and the pore throat of the target reservoir is mainly from 0.22 to $33.82 \mu \mathrm{m}$. Therefore, the size of the particle could be changed by adjusting the concentration of the acid liquid and the diverting agent, so as to achieve the purpose of blocking the high-permeability layer temporarily and meet the shunting requirements $[8,9]$.

2.4. Compatibility Evaluation. The compatibility tests for the chelate acid COA-1S and diverting agent COA-1P with injected water and formation water are carried out under the conditions of 20 and $60^{\circ} \mathrm{C}$, respectively. The results show that the compatibility of the two liquids with injected water and the formation water is good at different temperatures.

\section{Simulation Experiment Research of Online Shunt Acidification Experiment}

In order to further verify the feasibility of the technology, parallel core flow tests are carried out using two cores with different permeabilities selected from the corresponding reservoirs in Huanjiang oilfield $[10,11]$, and the effects of shunt and acidification are analyzed. The experiment temperature is $60^{\circ} \mathrm{C}$, and the experiment apparatus is the multifunctional shunt acidification experiment instrument which is self-developed. The results are shown in Figure 3 and Table 3.

Figure 3 is the pressure variation curve of the core of the $\mathrm{H} 2$ well after injecting acid and diverting agent. It can be seen that the pressure of core 1 changed little and the pressure of core 2 dropped after injecting 50\% COA-1S acid, indicating that acid is mainly injected into core 2 . After the injection of $6 \%$ COA- $1 \mathrm{P}$, the pressure of the two cores fluctuate greatly, and the pressure increases with the diverting agent and acid injecting sequentially, which indicate that the COA-1P played a temporary plugging role.
The pressure drops sharply with injection of stratum water after the acid liquid, which shows that COA-1P is dissolved by water and it does not plug the formation during the normal water injection.

Table 3 shows the results of permeability before and after the shunt acidification tests. It can be seen that the permeability of core 1 and 2 increase by 10.5 and 3.1 times, respectively, indicating that the diverting agent has effectively plugged core 2 and both the two cores have been completely acidified, and the effect of shunt acidification is good.

\section{Field Application Example}

4.1. Basic Situation and Analysis of Site Operation. On October 15, 2017, the onsite operation of online shunt acidification in well $\mathrm{H} 5$ of Huanjiang oilfield was carried out (shown in Figure 4), the dosage of shunt agent COA-1P was $2 \mathrm{~m}^{3}$, and the dosage of chelate acid was $17.4 \mathrm{~m}^{3}$. The operation procedures are as follows: (1) Pressure test and water squeeze. (2) The first stage of acid COA-1S was injected into the formation to remove reservoir choke and reduce the water injection pressure. The operation flow rate was $1.0 \mathrm{~m}^{3} /$ $\mathrm{h}-3.0 \mathrm{~m}^{3} / \mathrm{h}$, and the ratio of acid COA-1S to injected water was $1: 1.5$. The cumulative injection volume was $12 \mathrm{~m}^{3}$, of which $4.8 \mathrm{~m}^{3}$ acid liquid was squeezed from the well test valve to the reservoir, and the rest was injected from the normal process to the reservoir. (3) The second stage mixed solution of acid COA-1S and shunt COA-1P was injected into the formation, the flow rate of diverting agent was $1.0 \mathrm{~m}^{3} / \mathrm{h}$, and the injection volume of diverting agent was $2 \mathrm{~m}^{3}$; while the flow rate of acid solution was $1.2 \mathrm{~m}^{3} / \mathrm{h}$, and the cumulative injection volume of acid solution was $2.4 \mathrm{~m}^{3}$. (4) The third stage acid solution was injected into the formation. The operation flow rate was $1.2-3.0 \mathrm{~m}^{3} / \mathrm{h}$, and the ratio of acid COA-1S to injected water was $1: 1,10.2 \mathrm{~m}^{3}$ of acid liquid was squeezed from the oil pipe to the reservoir, and the other $10.2 \mathrm{~m}^{3}$ of water was injected from the distribution room to the casing pipe. (5) The water injection 


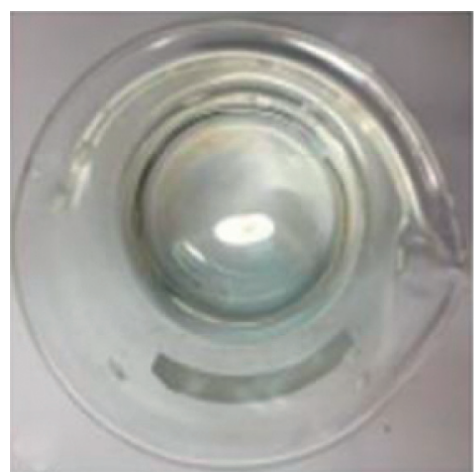

(a)

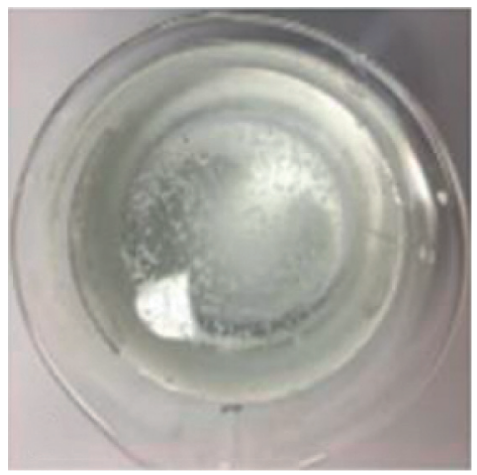

(d)

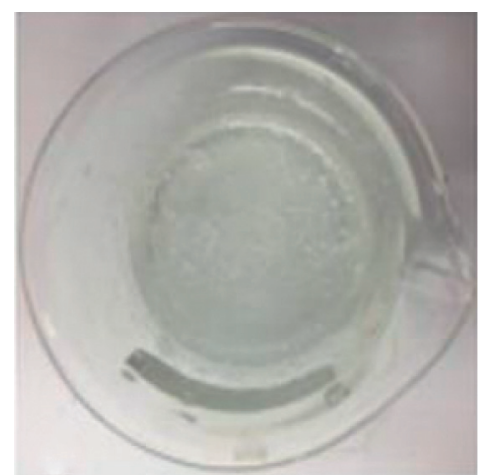

(b)

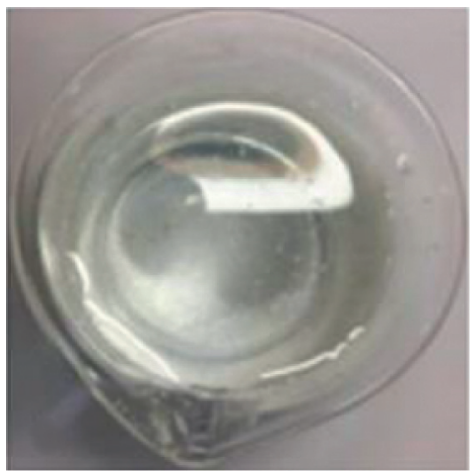

(e)

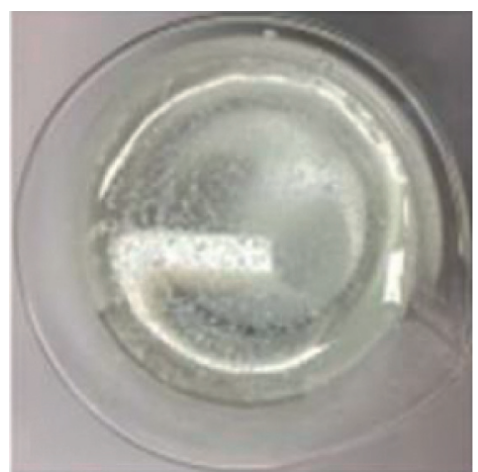

(c)

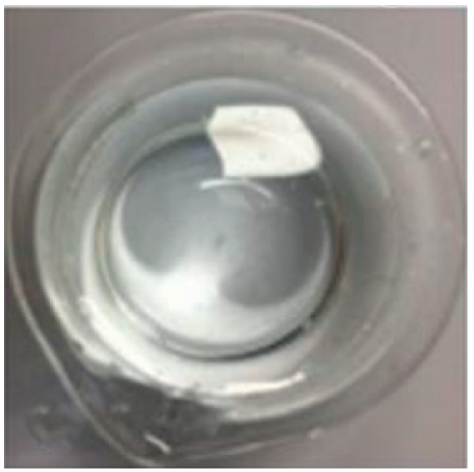

(f)

Figure 2: The solubility of water-soluble white particles. (a) Diverting agent + tap water; (b) diverting agent $+10 \mathrm{ml}$ of chelate acid; (c) $100 \mathrm{ml}$ of fresh water is added for the first time, $\mathrm{pH}<1$; (d) $300 \mathrm{ml}$ of fresh water is added for the second time, $\mathrm{pH}=4$; (e) $500 \mathrm{ml}$ of fresh water is added for the third time, $\mathrm{pH}=5$; and (f) $1000 \mathrm{ml}$ of fresh water is added for the fourth time, $\mathrm{pH}=7$.

TABLE 2: Particle size distribution of the mixed solution of COA-1P and COA-1S.

\begin{tabular}{|c|c|c|c|c|c|c|}
\hline \multirow{2}{*}{ Group } & \multirow{2}{*}{ COA-1P concentration $(\%)$} & \multirow{2}{*}{ COA-1S concentration $(\%)$} & \multirow{2}{*}{$\mathrm{pH}$} & \multicolumn{3}{|c|}{ Particle size $(\mu \mathrm{m})$} \\
\hline & & & & $d(0.1)$ & $d(0.5)$ & $d(0.9)$ \\
\hline 1 & 5 & 5 & $<1$ & 13.88 & 41.48 & 107.00 \\
\hline 2 & 10 & 10 & $<1$ & 15.73 & 42.43 & 110.12 \\
\hline 3 & 10 & - & 3 & 11.16 & 38.34 & 102.36 \\
\hline 4 & 10 & - & 5 & 10.54 & 38.24 & 100.45 \\
\hline
\end{tabular}

process was recovered. The water injection pressure was 16.5 $\mathrm{MPa}$, and the instantaneous flow rate was $1.0 \mathrm{~m}^{3} / \mathrm{h}$.

The operation curve is shown in Figure 5. It can be seen that, (1) when the sleeve valve was open, the acid liquid was squeezed into the formation and the pressure rose, indicating that it was difficult for the formation to absorb the water. (2) In the process of acid injection under high pressure, the operation pressure increased from 15.3 $\mathrm{MPa}$ to 17.3 MPa after the acid entered the well bottom, which indicated that the diverting agent played an effective role in plugging the high permeability layer. (3) At the end of acidification, the pressure of was $16.5 \mathrm{MPa}$ after the injection pump was stopped. After recovering the water injection process, the water injection pressure decreased from 17.3 to 16.5 $\mathrm{MPa}$. At present, the injection pressure was $14.9 \mathrm{MPa}$, which dropped $4.2 \mathrm{MPa}$ comparing with not operated before, indicating that the effect of acid liquid for plugging removal was obvious. (4) From 14:29 to 2:57, the whole construction cycle which was reduced at least 1 to 7 times was less than 13 hours, compared with the conventional profile adjustment technology for more than 7 days. In the process of acidification operation, there were no need of leakage of the water in the tube, pulling the original pipes out, changing acid, and flowback of the residual liquor. Online shunt acidizing technology greatly simplified the conventional acidification process and shortened the operation period. Moreover, in contrast to the soil pollution caused by the conventional profile adjustment technology, which needed to drain water and regurgitate reacted acid to the ground, it reduced the risk of safety and environmental pollution. Last, during the conventional profile adjustment construction, the well must be off when tripping operation and changing acid, but water and acid mixed liquid could be injected at the same time, and the original injection process 


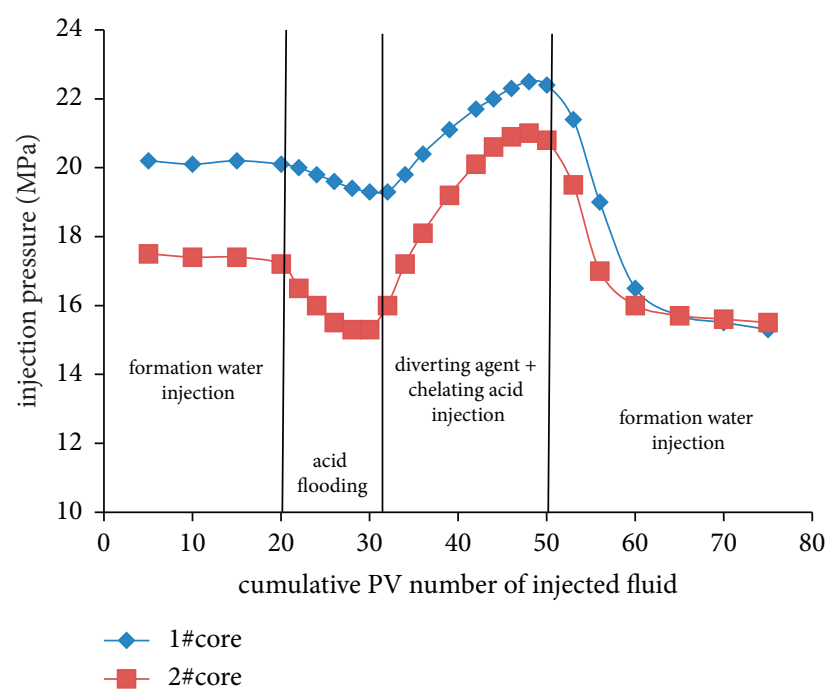

Figure 3: The curve of pressure of change of the core of the $\mathrm{H} 2$ well.

TABLE 3: Experimental results of $\mathrm{H} 2$ core diversion acidification.

\begin{tabular}{lcccc}
\hline $\begin{array}{l}\text { Core } \\
\text { number }\end{array}$ & $\begin{array}{c}\text { Depth } \\
(\mathrm{m})\end{array}$ & $\begin{array}{c}\text { Initial permeability } \\
\left(10^{-3} \mu \mathrm{m}^{2}\right)\end{array}$ & $\begin{array}{c}\text { Permeability after diversion acidification } \\
\left(10^{-3} \mu \mathrm{m}^{2}\right)\end{array}$ & $\begin{array}{c}\text { Permeability increasing } \\
\text { multiple }\end{array}$ \\
\hline 1 & 2631.4 & 0.12 & 1.26 & 10.5 \\
2 & 2640.3 & 0.64 & 1.98 & 3.1 \\
\hline
\end{tabular}

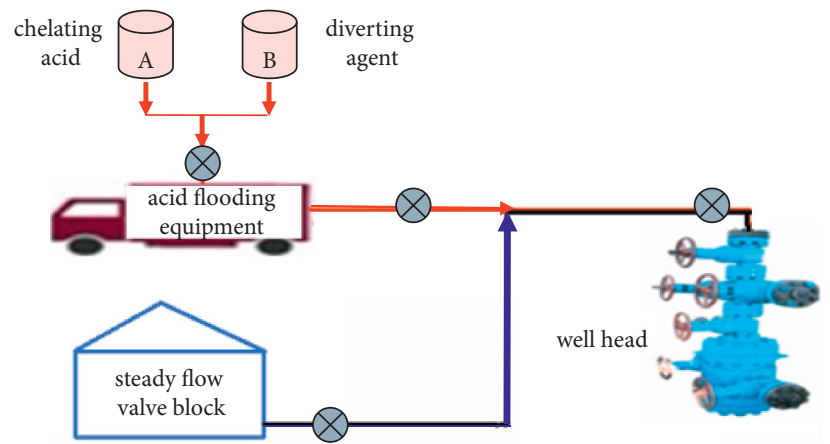

Figure 4: Flow chart of the online diversion acidizing operation process.

would not be stopped, which did not affect the normal water injection of water injection wells in the process of online shunt acidizing.

4.2. Profile Adjustment. Figure 6 shows the variation of the water absorption profile before and after the online shunt acidification of the $\mathrm{H} 5$ well. It can be seen that the upside of operated wells (2628-2638 m) absorbed water weakly and the lower section of wells $(2638-2643 \mathrm{~m})$ showed obvious characteristics of water absorption. The maximum water absorption intensity was $3.47 \mathrm{~m}^{3} / \mathrm{d} \cdot \mathrm{m}$, and the degree of water absorption was only $28.5 \%$. After the online shunt acidification, the upper and lower section of wells absorbed balanced water amount, the average water absorption intensity was $1.42 \mathrm{~m}^{3} / \mathrm{d} \cdot \mathrm{m}$, and the degree of water absorption was $50.9 \%$. The results demonstrated that the online shunt acidification could achieve well-proportioned acid distribution and improve the water absorption profile of the operated well effectively.

4.3. Effect of Depressurization and Injection Augment. Figure 7 shows the water injection curve before and after online shunt acidification of the $\mathrm{H} 5$ well. Before acidification, the oil pressure was $19.1 \mathrm{MPa}$, the allocation injection amount of water was $25 \mathrm{~m}^{3} / \mathrm{d}$, and the actual water injection amount was $15 \mathrm{~m}^{3} / \mathrm{d}$. After acidification, the oil pressure was 14.9 $\mathrm{MPa}$, the allocation injection amount of water was $25 \mathrm{~m}^{3} / \mathrm{d}$, and the actual daily injection amount was $25 \mathrm{~m}^{3} / \mathrm{d}$. The water absorption index increased two times as before, and the effect of decrease of pressure and increase water injection was obvious. 


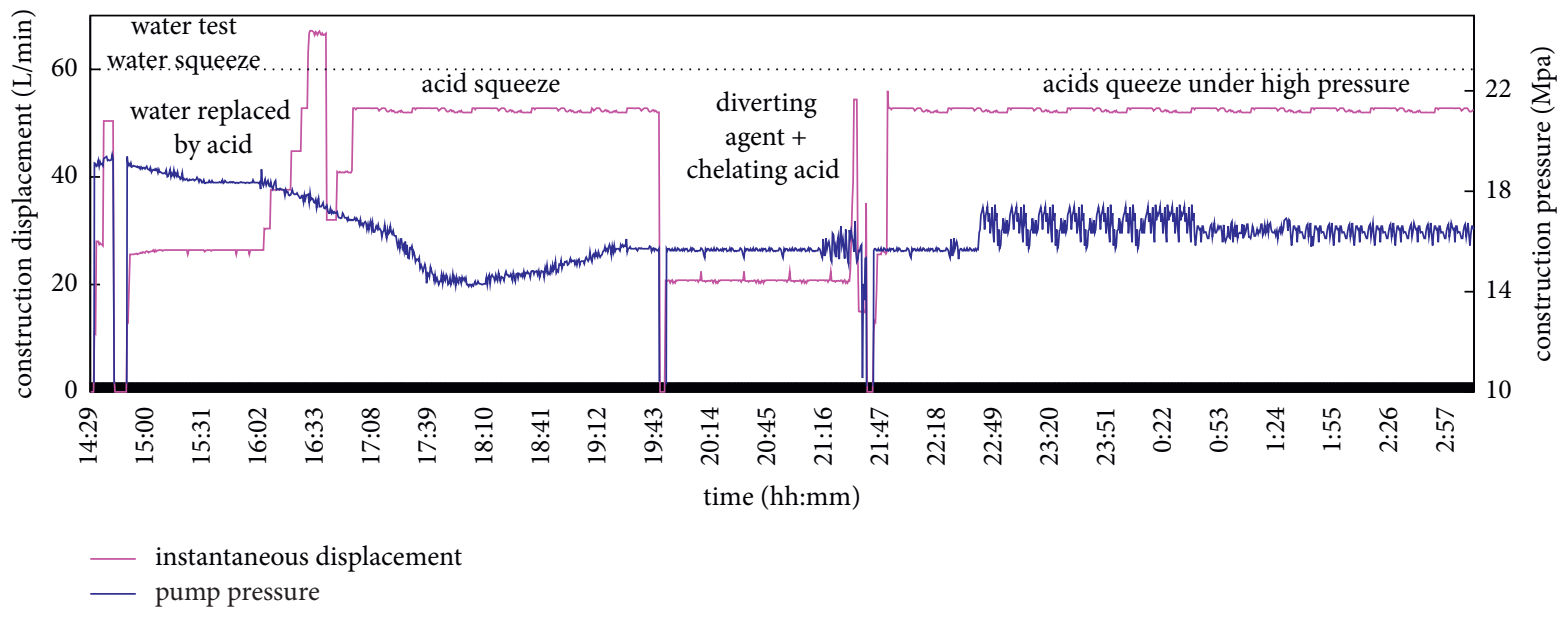

FIgURE 5: The operation curve of the online diversion acidification of the H5 well.

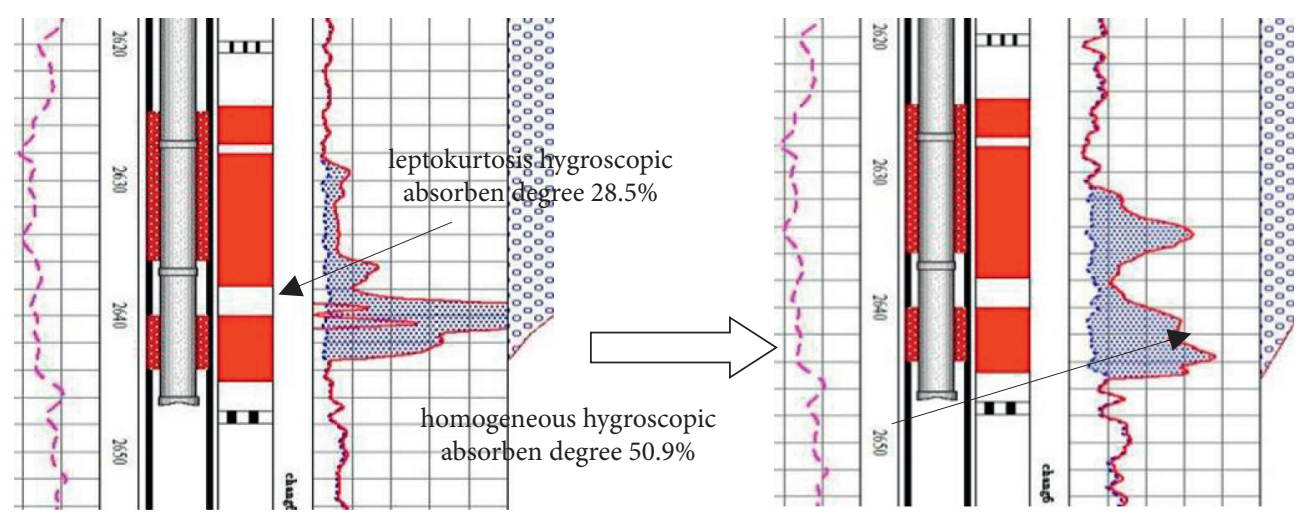

FIgure 6: Absorption profile of the H5 well.

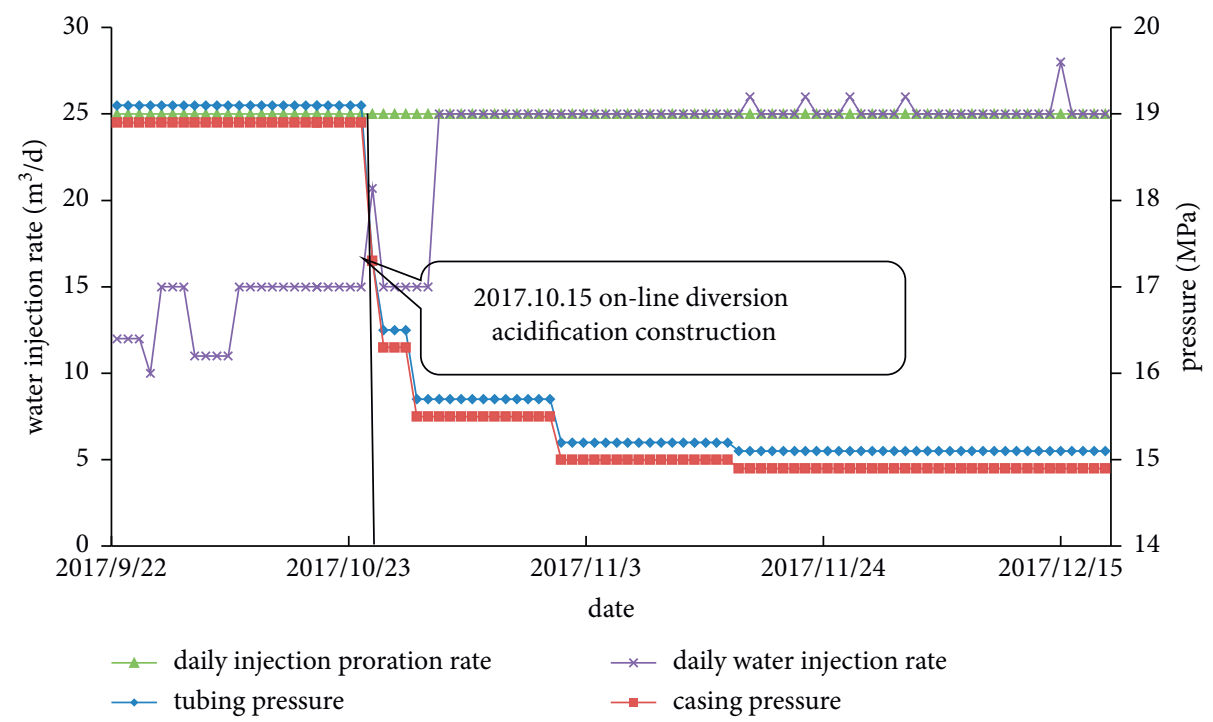

Figure 7: The water injection curve of the H5 well before and after online diversion acidification. 


\section{Conclusions}

(1) Compared with conventional mud acid and multihydrogen acid, chelate acid COA-1S is superior in corrosion rate, retardation capacity, and chelating ability, which could slow down acidification rate, increase the time of operation, prolong acidification distance, reduce secondary precipitation of barium and strontium, and improve the effect of acidification.

(2) The water-soluble diversion agent COA-1P could produce chemical particles when in contact with acid liquid and can make the proportional distribution of acid in the objective layer and improve the utilization of acid liquid, as well as the longitudinal water absorption profile of wells underinjection. Moreover, the diversion agent COA-1P could completely dissolve in the formation water and the injected water, which did not cause secondary plugging to the formation.

(3) The online shunt acidification augmented injection technology was successfully applied in the H5 well of Huanjiang oilfield. It is proved that the technology had good applicability for the similar reservoirs and had important significance for improving the effect of water injection in similar oilfields.

(4) Based on the different blockage reasons of each block of the ultra-low-permeability reservoir in Huanjiang Oilfield, the continuous injection online diversion acidification technology will act as the main part, with different other injection parts, such as inhibiting scale part and preventing clay swelling part and nanoaugmented injection, forming a set of online injection process systems, to solve the problems of high-pressure water wells underinjection in ultralow-permeability reservoirs effectively.

\section{Data Availability}

The data used to support the findings of this study are included within the article.

\section{Conflicts of Interest}

The authors declare no conflicts of interest regarding the publication of this paper.

\section{Acknowledgments}

This work was financially supported by the National Natural Science Foundation of China (51402220), Key Project of Hubei Education Department (D20191503), and Wuhan Institute of Technology Science Foundation (K201801).

\section{References}

[1] W. Chen, X. F. Yuan, and J. C. Guo, "Application and evaluation on multi-hydro acid deep diversion acidizing technology in Donghe oil-field," Chemical Engineering of Oil \& Gas, vol. 40, pp. 285-288, 2011.

[2] X. Liu, L. Q. Zhao, Z. Yang, and Y. G. Liu, "Application of acidizing technology with original production string in bohai oilfield," Oil Drillinge Production Technology, vol. 26, pp. 47-49, 2004.

[3] Y. Fan and M. J. Economides, "Fracturing fluid leakoff and net pressure behavior," in Proceedings of the Frac \& Pack Stimulation, Society of Petroleum Engineers of AIME, Article ID 29988, Beijing, China, November 1995.

[4] P. Y. Gao, P. L. Liu, H. Liu, X. H. Meng, J. C. Gao, and S. Y. Fu, "Research on water soluble micro-particle diverting agent SA2," DFCF, vol. 29, pp. 67-70, 2012.

[5] P. L. Liu, Y. G. Liu, L. Q. Zhao, and J. M. Chen, "Study and application on acidizing high permeability \& high porosity reservoir in Bohai bay oil-field," Journal of Southwest Petroleum Institute, vol. 27, pp. 52-56, 2005.

[6] N. Water, L. Jairo, and M. Ataur, "Multilayered reservoir stimulation: case study of effective acid diversion achieved using the associative polymer treatment diverting agent," in Proceedings of the Khuff Carbonate Reservoir Wells, Saudi A Rabia'S Ghawar Field, Society of Petroleum Engineers of AIME, Article ID 123442, Jakarta, Indonesia, August 2009.

[7] P. L. Liu, F. Li, X. T. Lan, C. L. Liu, and N. Y. Li, "Development of new self-diverting acid for sandstone reservoirs offshore," Drilling and Production Technology, vol. 40, pp. 90-93, 2017.

[8] M. Liu, S. Zhang, J. Mou, F. Zhou, and Y. Shi, "Diverting mechanism of viscoelastic surfactant-based self-diverting acid and its simulation," Journal of Petroleum Science and Engineering, vol. 105, pp. 91-99, 2013.

[9] L. P. Ma, T. Zhang, L. H. Yang, and L. J. Zheng, "The laboratory research on self diverting acidizing and its application in oilfield," Offshore Oil, vol. 40, pp. 90-93, 2017.

[10] D. Taylor, P. S. Kumar, and D. Fu, "Viscoelastic surfactant based self-diverting acid for enhanced stimulation in carbonate reservoirs," in Proceedings of the SPE European Formation Dam-Age Conference, Hague, Netherlands, May 2003.

[11] S. B. Wang, H. R. Wang, J. C. Guo, and J. Lan, "Research and application of self-diverting mud acid in sandstone reservoir acidizing," Oilfield Chemistry, vol. 32, pp. 490-493, 2015. 